\title{
Proposta de método para a escolha de áreas de drenagem amostrais e suas relações com variáveis hidrológicas na região sudeste do Estado de São Paulo - Brasil
}

\author{
Proposal for a method for choosing sample drainage areas \\ and their relations with water variables in the southeast \\ region of the state of São Paulo - Brazil
}

Ana Claudia Pereira Carvalho ${ }^{1}$, Ana Paula Pereira Carvalho ${ }^{1}$, José Augusto Di Lollo², Eduardo Goulart Collares ${ }^{3}$, Reinaldo Lorandi ${ }^{1}$, Luiz Eduardo Moschini ${ }^{1}$ 1Universidade Federal de São Carlos - UFSCar, São Carlos, SP, Brasil. E-mails: anaclaudiaengamb@gmail.com,
appc.engambiental@gmail.com, lorandir@gmail.com, lemoschini@ufscar.br
2Universidade Estadual Paulista “Júlio de Mesquita Filho”, Ilha Solteira, SP, Brasil. E-mail: jose.lollo@unesp.br
3Universidade do Estado de Minas Gerais, Passos-MG, Brasil. E-mail: eduardo.collares@uemg.br

Como citar: Carvalho, A. C. P., Carvalho, A. P. P., Di Lollo, J. A., Collares, E. G., Lorandi, R., \& Moschini, L. E. (2020). Proposta de método para a escolha de áreas de drenagem amostrais e suas relações com variáveis hidrológicas na região sudeste do Estado de São Paulo - Brasil. Revista de Gestão de Água da América Latina, 17, e10. https://doi.org/10.21168/rega.v17e10.

RESUMO: 0 objetivo do trabalho consistiu em avaliar o comportamento hidrológico de sub-bacias hidrográficas consideradas morfometricamente semelhantes, em função das variações pluviométricas. Os métodos adotados neste trabalho envolveram seis etapas, sendo elas: delimitação das sub-bacias hidrográficas; cálculo dos índices morfométricos; análises de agrupamentos; escolha das sub-bacias hidrográficas objetos de estudo; coleta de dados hidrológicos; e análise relativa da precipitação e vazão. Com base nos métodos empregados foram escolhidos quatro pares de sub-bacias hidrográficas que abrangem a Bacia Hidrográfica do Rio Piracicaba (BHRP) com área de 12.655,01 km² e localizada no sudeste do estado de São Paulo. A análise de correlação (precipitação e vazão) por pares das sub-bacias hidrográficas permitiu a obtenção de um diagnóstico preliminar referente ao comportamento hidrológico das áreas, sem a necessidade inicial de utilizar outros atributos ambientais relacionados ao meio físico.

Palavras-chave: Sub-bacias Hidrográficas; Análise de Agrupamentos; Disponibilidade Hídrica; Vazão; Piracicaba.

ABSTRACT: The objective of the work was to evaluate the hydrological response of hydrographic sub-basins considered morphometrically similar, in function of the pluviometric variations. The methods adopted in this work involved six steps, they being: delimitation of the sub-basins; calculation of morphometric indices; cluster analysis; choice of the sub-basins; collect of hydrological data; and relative analysis precipitation and streamflow. Based on the methods employed, four pairs of watersheds covering the Piracicaba River Basin (BHRP - 12.655,01 km²), located in the southeast of the state of São Paulo. The correlation analysis (precipitation and flow) by pairs of the watersheds allowed the obtaining of a preliminary diagnosis regarding the hydrological response of the areas, without the initial need to use other environmental attributes related to the physical environment.

Keywords: Sub-basin; Cluster Analysis; Water Availability; Streamflow; Piracicaba.

\section{INTRODUÇÃO}

A oferta de água per capita em várias regiões do planeta está diminuindo constantemente, uma das explicações é o crescimento da população mundial quando relacionado com a água disponível em várias áreas do mundo. A população no âmbito mundial cresceu de 2 bilhões em 1950 para um número atual de 7,4 bilhões, considerando basicamente a mesma oferta de água. Porém, há motivos pelos quais

Recebido: Novembro 25,2019 - Revisado: Maio 06, 2020 - Aceito: Junho 23, 2020 
essa conclusão não é global, pois a espacialização do crescimento populacional não é constante (Lakshmi et al., 2018).

Aproximadamente 4 bilhões de pessoas, que em números representa quase dois terços da população mundial, suportaram pelo menos um mês do ano uma escassez hídrica grave (Mekonnen \& Hoekstra, 2016).

O Brasil é um país que apresenta privilégios quanto à disponibilidade hídrica total, porém a oferta da água é diferente no território, bem como, no decorrer do ano. Além disso, vale ressaltar os seus diversos usos e a infraestrutura hídrica apropriada para o seu aproveitamento e conservação. O entendimento sobre abundância de água está sendo modificado pelo conceito de que a oferta de água é finita atribuída de valor econômico, priorizando cada vez mais a importância de realizar o balanço entre a disponibilidade e a demanda hídrica (Agência Nacional de Águas, 2019).

Nas últimas duas décadas, pôde-se contabilizar que o uso da água é crescente, totalizando aproximadamente um aumento de $80 \%$ no total retirado. A tendência é que continue alavancando a demanda, pois se estima um acréscimo de $24 \%$ até o ano de 2030 (Agência Nacional de Águas, 2019). A demanda hídrica mundial continuará crescendo a uma percentagem similar até 2050, correspondendo um acréscimo entre $20 \%$ e $30 \%$ quando relacionado com o patamar atual de uso do recurso (Burek et al., 2016).

De acordo com o World Water Development Report (2019), essa aceleração constante na demanda é recorrente do uso crescente nos países em desenvolvimento e economias emergentes. No entanto, o uso de água per capita na maioria dos países subdesenvolvidos continua muito abaixo quando comparado com os países desenvolvidos. A mudança na quantidade de água disponível também está associada com as alterações climáticas e com o crescimento da população (Suzdaleva, et al., 2017; Lakshmi et al., 2018, Jaramillo \& Nazemi, 2018).

Além das várias pressões que a demanda impõe sobre os recursos hídricos disponíveis, as mudanças climáticas empregam outras pressões ao gerenciamento do recurso. Devido o aumento da evaporação por meio da elevação na temperatura, as alterações climáticas proporcionam eventos extremos com maior frequência e intensidade relacionados à água, como a ocorrência de inundações e secas (Makarigakis \& Jimenez-Cisneros, 2019). A mudança da precipitação terá ocorrência em várias escalas temporais, variando de intra a interanual e podendo ser mais longas (Sala et al., 2015). As intervenções antrópicas frequentemente derivam na contaminação dos recursos hídricos e intensificam os efeitos das mudanças climáticas, além do mais, podem alterar a dinâmica do meio ambiente e atenuar os serviços ecossistêmicos fornecidos. Deste modo, a segurança hídrica dos países está comprometida, inserindo desafios difíceis aos países subdesenvolvidos para enfrentá-la (Makarigakis \& Jimenez-Cisneros, 2019).

Mesmo que os reservatórios naturais e artificiais sejam favoráveis para aumentar os recursos hídricos disponíveis para a humanidade, o foco essencial nas avaliações de recursos hídricos é o fluxo de água (Oki \& Kane, 2006). 0 aumento da demanda de água e a diminuição da disponibilidade de água doce em uma área podem causar danos à saúde humana, à qualidade do ecossistema e aos recursos naturais (Kaewmai et al., 2019), propagando a pressão sobre os recursos hídricos disponíveis no mundo em termos de quantidade e qualidade (Jodar-Abellan et al., 2019).

A disponibilidade hídrica é uma temática de importância em escala global e seu conhecimento é indispensável para o desenvolvimento da sociedade. Para avaliar a disponibilidade dos recursos hídricos, a vazão dos canais de drenagem é uma variável que se destaca, nos últimos anos recebeu interferência expressiva devido às alterações climáticas e antrópicas em bacias hidrográficas (Wei et al., 2014).

Um conjunto de dados hidrométricos e meteorológicos são utilizados para a realização de estudos hidrológicos, para obtenção dos dados se faz necessário à coleta diretamente no campo apresentando precisão apropriada para os fins almejados (Dirección General de Aguas, 1991). Um dos dados refere-se a vazão, sendo essencial, pois para a gestão e gerenciamento adequado dos recursos hídricos são necessários registros precisos de vazão (U.S. Bureau of Reclamation, 2001).

A hidrodinâmica trata-se do estudo fundamental para entender a dinâmica de um rio principalmente quando os fatores do clima exercem impactos que alteram o seu comportamento. Diante disto, o fluxo do rio pode alterar extremamente devido as ações antropogênicas, como uso e cobertura do solo, onde as modificações ocorrem no entorno das margens do rio ou no interior de bacias hidrográficas (Walter \& Tullos, 2010). Para compreender e gerir adequadamente uma região hidrológica é fundamental realizar a caracterização de maneira abrangente das bacias hidrográficas, bem como suas redes fluviais (Gaucherel et al., 2017). As bacias hidrográficas situadas próximas em paisagem semelhante apresentam descargas específicas similares (Karlsen et al., 2016). 
Diante deste contexto, o objetivo principal deste trabalho consistiu em avaliar o comportamento hidrológico de sub-bacias hidrográficas consideradas morfometricamente semelhantes, em função das variações pluviométricas.

\section{MATERIAIS E MÉTODOS}

\section{1. Área de Estudo}

As áreas de estudo deste trabalho estão situadas na área de drenagem da Bacia Hidrográfica do Rio Piracicaba (BHRP) que apresenta oitava ordem de ramificação, localizada em sua maior parte no sudeste do estado de São Paulo (Figura 1). A BHRP se enquadra como uma das bacias da unidade de gerenciamento de recursos hídricos UGRHI-05, abrangendo $12.655,01 \mathrm{~km}^{2}$.

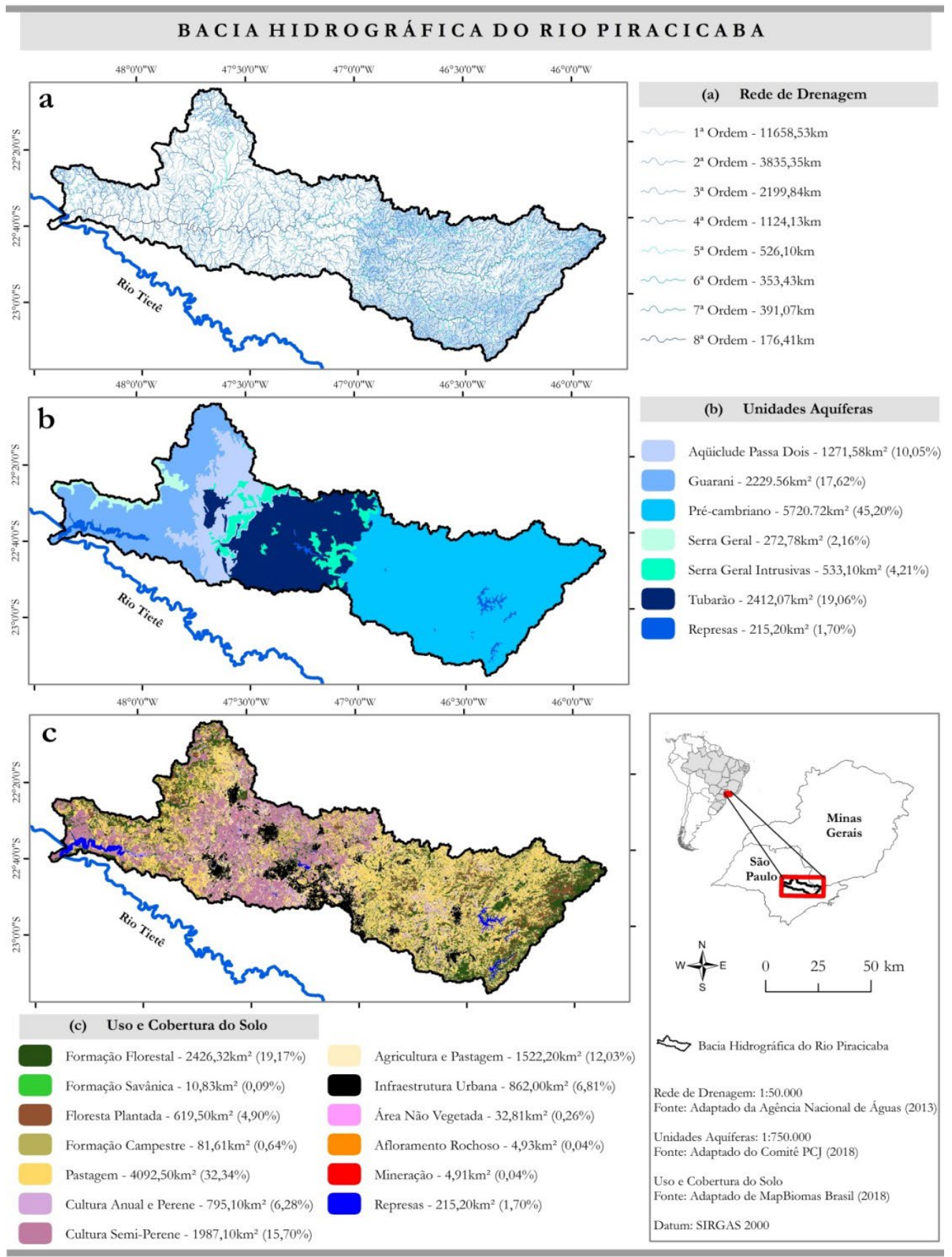

Figura 1 - Localização da Bacia Hidrográfica do Rio Piracicaba (BHRP). 
Em termos litoestratigráficos, a região da BHRP é composta por terrenos predominantemente sedimentares Fanerozóicos (Mesozóicos), associados à um derrame magmático básico situados na porção oeste da bacia hidrográfica e, por terrenos cristalinos do Fanerozóico (Eopaleozóico) e Proterozóico Inferior encontrados na porção leste (São Paulo SICCT-PROMOCET-IPT, 1981). Esta característica associa-se com o tipo de drenagem que a BHRP apresenta em sua área de abrangência, considerando que a região oeste se destaca uma rede de drenagem mais esparsa, devido a propriedade física dos terrenos, que possibilita maior infiltração de água favorecendo assim a recarga dos aquíferos. Por outro lado, a região leste apresenta rede de drenagem densa do tipo dendrítica, as características desta região contribuem com a oferta hídrica superficial distribuída em menores áreas de drenagem.

As unidades aquíferas da BHRP são provenientes das unidades geológicas existentes, sendo $50,63 \%$ das bacias apresentam aquíferos aflorantes de porosidade de fraturas/fissuras (Serra Geral, Diabásio, Cristalino e Pré-Cambriano) e 49,37\% de porosidade intergranular, sendo que 47,89\% representa aquíferos livre e semi-confinado (Cenozóico, Bauru, Guarani-Botucatu, Passa Dois e Tubarão) e apenas 1,48\% constitui o aquífero confinado (Guarani-Botucatu confinado) (Engenharia e Consultoria em Recursos Hídricos e Meio Ambiente Ltda, 2007).

As unidades geológicas na porção centro-oeste pertencem à Bacia Sedimentar do Paraná, que engloba vários tipos litológicos agrupados em quatro grandes domínios geológicos: Embasamento Cristalino; Rochas Sedimentares; Rochas Ígneas Básicas; Coberturas Sedimentares Cenozóicas. Enquanto na porção leste, a geologia é caracterizada pelo domínio tectônico que representa aos Maciços de Guaxupé e Socorro (Engenharia e Consultoria em Recursos Hídricos e Meio Ambiente Ltda, 2007).

A BHRP se encontra dividida em três unidades geomorfológicas estruturais, sendo: Depósitos Sedimentares Quaternários; Bacias e Coberturas Sedimentares Fanerozóicas; e Cinturões Móveis Neoproterozóicos. 0 primeiro domínio apresenta menor ocorrência na BHRP, e concentra-se em pequenas áreas da região centro-oeste representadas por planícies e terraços com declividade baixa, sendo encontrados também, em depressões sobre depósitos de sedimentos horizontais e sub-horizontais de terraços fluviais. Quanto às Bacias e Coberturas Sedimentares Fanerozóicas, se apresentam em maior evidência na BHRP, mais especificamente na direção centro-oeste até a foz do Rio Piracicaba, compreendendo planaltos e chapadas desenvolvidos sobre substrato rochoso sedimentar horizontal e sub-horizontal. 0 último domínio se localiza na porção leste da BHRP estendendo para a região central, é caracterizado por planaltos, depressões envolventes e alinhamentos serranos em terrenos deformados por dobras e falhas (Agência das Bacias PCJ, 2018).

Em função dessa diversidade geológica e fisiográfica, foram selecionados quatro pares de sub-bacias de quarta ordem, de forma a representar essa variabilidade.

Quanto ao clima, a região paulista apresenta índices de precipitação pluviométrica que variam entre 1200 e $1800 \mathrm{~mm} /$ ano. Ressalta-se que as maiores precipitações que ultrapassam os $2000 \mathrm{~mm} /$ ano, ocorrem nos trechos das cabeceiras dos canais de drenagem que formam o rio Piracicaba, localizados a leste do município de Bragança Paulista. Na parcela da bacia localizada no Estado de Minas Gerais, a média anual de precipitação ultrapassa os $1500 \mathrm{~mm}$, enquanto a evaporação potencial anual oscila entre 650 e $800 \mathrm{~mm}$ (Companhia Brasileira de Projetos e Empreendimentos, 2010).

\subsection{Etapas Metodológicas}

Os procedimentos metodológicos adotados neste trabalho envolveram 6 etapas principais que estão apresentadas sinteticamente na Figura 2. 


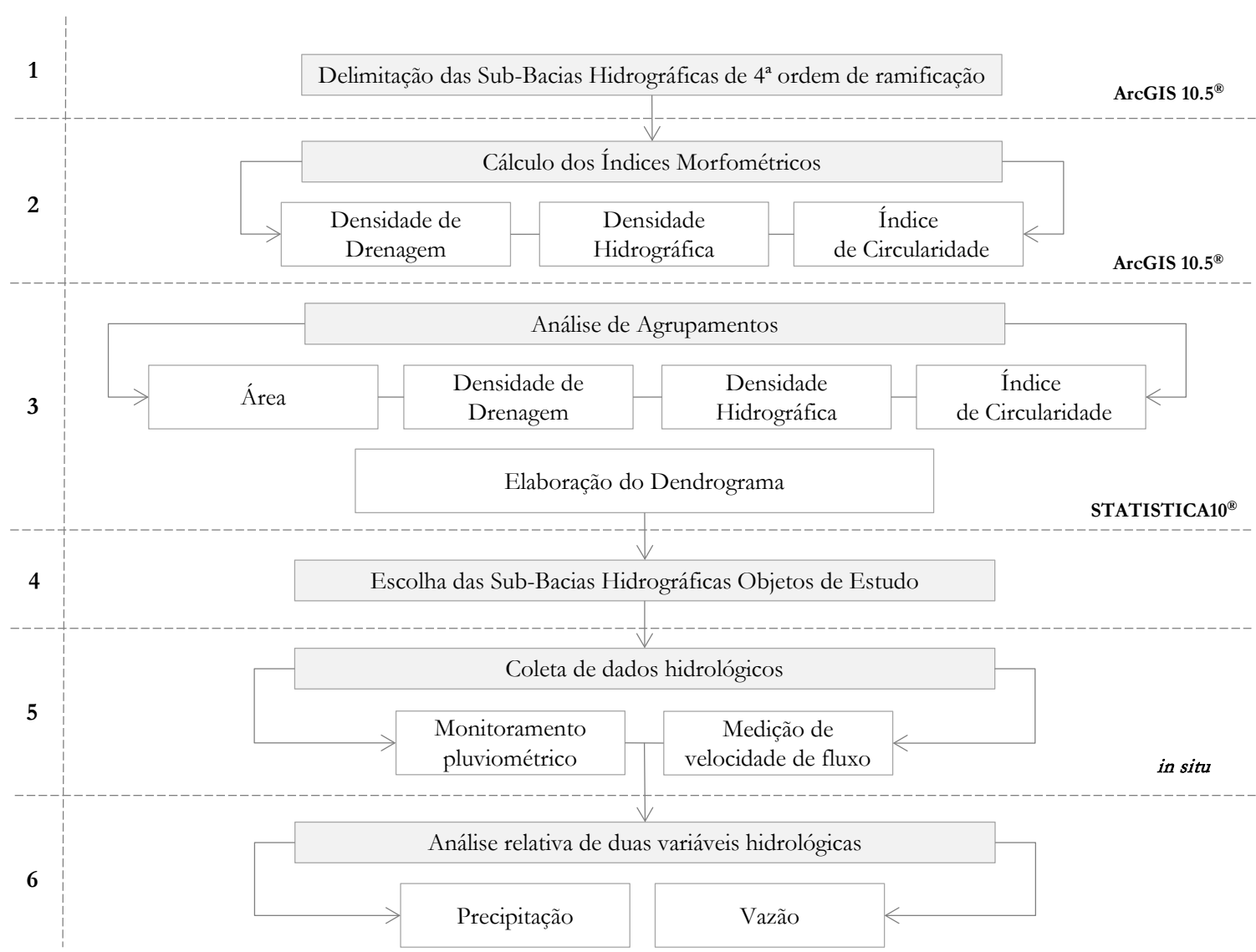

Figura 2 - Etapas metodológicas realizadas para a elaboração deste trabalho.

Para a escolha das sub-bacias hidrográficas objeto de estudo, foi inicialmente considerada a ordem de ramificação dos canais de drenagem. A partir de então, foram definidas sub-bacias hidrográficas de $4^{\mathrm{a}}$ ordem situadas na BHRP, por serem áreas que apresentam em sua extensão territorial uma heterogeneidade suficiente dos atributos físicos e antrópicos, o que permite um estudo mais pormenorizado da disponibilidade e demanda hídrica destas áreas.

A delimitação das sub-bacias hidrográficas de $4^{\text {a }}$ ordem de ramificação foi executada no software ArcGIS10.5 ${ }^{\circledR}$, na escala de 1:50.000. Os dados vetoriais utilizados foram as curvas de nível e os pontos cotados extraídos das cartas topográficas do Instituto Brasileiro de Geografia e Estatística (Instituto Brasileiro de Geografia e Estatística, 2019), e a rede de drenagem disponível na plataforma GeoNetwork da Agência Nacional de Águas (ANA), sendo que a classificação hierárquica pluvial foi executada considerando o método de Strahler (1957). Vale ressaltar que os limites das sub-bacias hidrográficas de $4^{\mathrm{a}}$ ordem de ramificação, foram definidos sem o uso de algoritmo específico de delimitação automática, ou seja, delimitado de forma manual em tela, considerando a base topográfica oficial.

Logo após o estabelecimento das sub-bacias hidrográficas de $4^{a}$ a ordem, além da Área (A) em $\mathrm{km}^{2}$ foram calculados três índices morfométricos (Tabela 1). Os três índices morfométricos foram adotados por associarem-se diretamente com a geometria e a capacidade hidrológica das sub-bacias hidrográficas da BHRP. O cálculo foi realizado com o auxílio das ferramentas do software ArcGIS10.5 ${ }^{\circledR}$. 
Tabela 1 - Índices morfométricos utilizados para a análise de agrupamentos das sub-bacias hidrográficas de 4⿳ạ ordem de ramificação.

\begin{tabular}{|c|c|}
\hline Índice Morfométrico / Autor & Fórmula \\
\hline Densidade de Drenagem (Dd) / Horton (1945) & $\begin{array}{c}\mathrm{Dd}=\frac{\sum \mathrm{L}}{\mathrm{A}} \\
\sum \mathrm{L}=\text { comprimento total dos canais de drenagem } \\
\mathrm{A}=\text { área da bacia }\end{array}$ \\
\hline Densidade Hidrográfica (Dh) / Horton (1945) & $\begin{array}{c}\mathrm{Dh}=\frac{\mathrm{n}}{\mathrm{A}} \\
\mathrm{N}=\text { número de canais de drenagem de } 1^{\underline{a}} \text { ordem } \\
\mathrm{A}=\text { área da bacia }\end{array}$ \\
\hline Índice de Circularidade (Ic) / Miller (1953) & $\begin{array}{c}\mathrm{Ic}=\frac{\mathrm{A}}{\mathrm{Ac}} \\
\mathrm{A}=\text { área da bacia } \\
\mathrm{Ac}=\text { área do círculo cujo perímetro é igual ao da } \\
\text { bacia }\end{array}$ \\
\hline
\end{tabular}

Após os cálculos, os dados quantitativos foram tabulados em planilha do software Excel, no formato .xls. A Figura 3 apresenta a distribuição da área e dos três índices morfométricos das sub-bacias hidrográficas de $4^{a}$ ordem de ramificação. A matriz de dados originais foi inserida no software STATISTICA $10^{\circledR}$ para a análise do nível de similaridade entre a área das sub-bacias hidrográficas e os três índices morfométricos considerados, os quais foram analisados com a mesma importância. Optou-se por não utilizar mais parâmetros morfométricos, evitando-se a subjetividade da análise estatística.

A técnica utilizada neste trabalho foi a análise de agrupamentos, que possibilita realizar a classificação de valores de uma matriz de dados em grupos discretos. 0 método adotado foi o pareado igualmente ponderado, o qual se mostrou mais adequado aos demais métodos como, pareado proporcionalmente ponderado, ligação simples e composta, variância mínima, pois, a princípio se busca pelos mais altos coeficientes de associação mútua. Posteriormente, esses pares de casos concedem valores médios que formam um novo elemento singular. Para o cálculo de valores médios, emprega-se o mesmo peso aos elementos que são integrados. Quanto ao coeficiente de similaridade, adotou-se o coeficiente de distância, por agrupar melhor as amostras (sub-bacias hidrográficas de 4 a ordem de ramificação) do que a utilização do coeficiente de correlação indicado para agrupar variáveis (Landim, 2011).

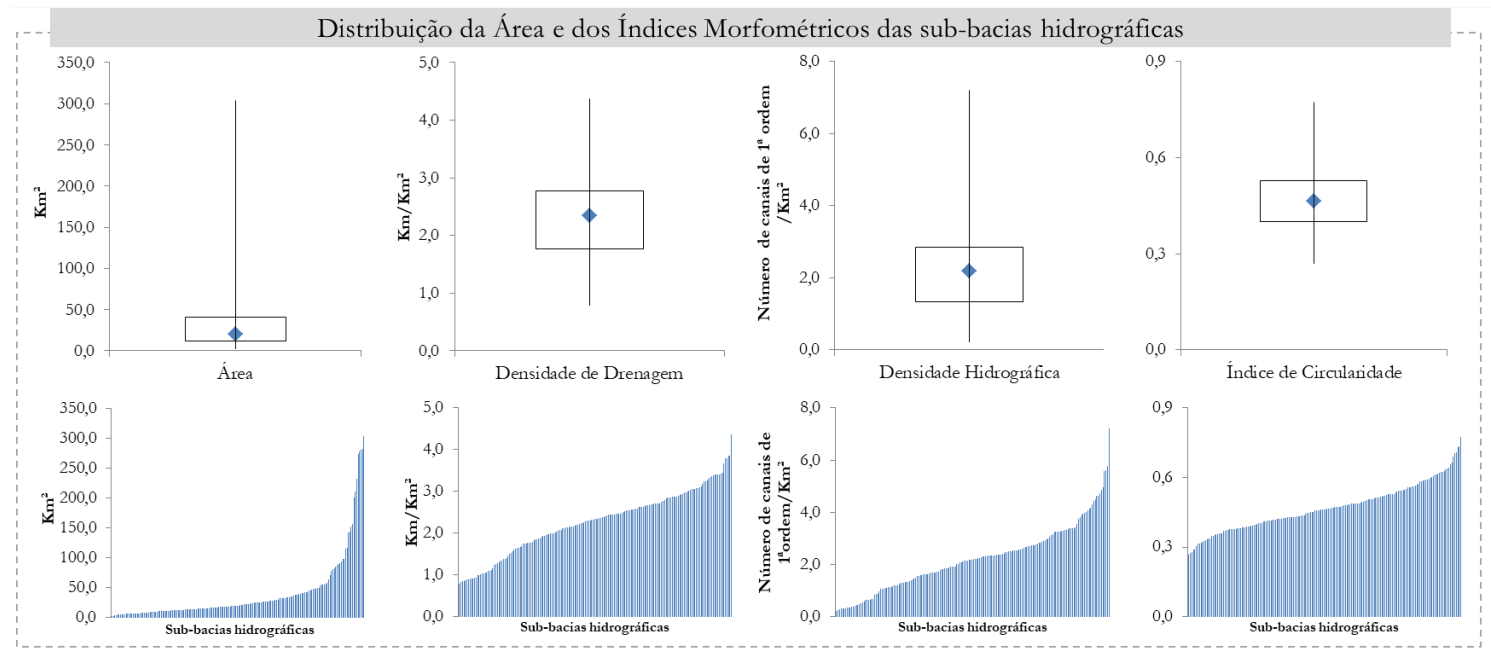

Figura 3 - Distribuição da área e dos índices morfométricos das 180 sub-bacias hidrográficas de 4⿳⺈ ordem de ramificação.

Posteriormente, foi elaborado um dendrograma para a identificação dos pares de sub-bacias que são semelhantes quanto aos valores dos índices calculados. Após esta análise foram escolhidos 4 pares de sub-bacias hidrográficas para a realização do trabalho. Ressalta-se que a escolha destes pares levou 
em consideração a posição geográfica das sub-bacias hidrográficas, optando-se desta forma, por pares localizados nas extremidades e nas porções centrais da BHRP.

Com relação à coleta dos dados hidrológicos nas sub-bacias hidrográficas objetos de estudo, foram instalados pluviômetros digitais para a aferição mensal da precipitação em mm. Vale ressaltar, que as leituras foram realizadas no final de cada mês, entre maio a outubro de 2019. Os pluviômetros foram instalados na área de abrangência de cada uma das sub-bacias hidrográficas escolhidas (Figura 5). Os valores de precipitação no mês de abril foram adquiridos por meio do Centro Integrado de Informações Agrometeorológicas (Centro Integrado de Informações Agrometeorológicas, 2019) devido ter sido o mês de instalação dos pluviômetros, a qual ocorreu em dias diferentes para cada subbacia hidrográfica objeto de estudo, impossibilitando a aferição mensal total.

A vazão pode ser obtida por meio do produto entre área e velocidade de fluxo. Normalmente, essa mensuração é realizada com base na subdivisão de uma seção transversal em seguimentos entendidos como subseções verticais e/ou áreas parciais. Assim, o fluxo total trata-se do somatório dos produtos das subseções verticais da seção transversal e suas respectivas velocidades médias (U.S. Geological Survey, 2010).

Além da precipitação, outro dado coletado em campo neste mesmo período foi a velocidade de fluxo (m/s) por meio do equipamento do tipo molinete hidrométrico FP111, fabricado pela Global Water ${ }^{\circledR}$. Para o cálculo da vazão em $\mathrm{m}^{3} / \mathrm{s}$ foi necessário a aplicação do método de batimetria, que permitiu obter a altura do nível de água em cada ponto para aferição da velocidade de fluxo.

Este trabalho adotou o método detalhado para considerar as distâncias entre verticais para a aferição da velocidade de fluxo na seção transversal do rio em cada sub-bacia hidrográfica e também para considerar a posição na vertical com relação à profundidade da mesma. Os critérios adotados seguiram as Normas e Recomendações Hidrológicas, do ano de 1967 e o Manual para Serviços de Hidrometria, do ano de 1977, elaborados pelo Departamento de Águas e Energia Elétrica (Santos et al., 2001). 0 método detalhado utilizado permite a aferição adequada de vazão em sub-bacias hidrográficas de pequeno a médio porte.

A distância entre verticais para a seção transversal do rio em cada sub-bacia hidrográfica variou de 0,30m, 0,50m e 1m, sendo que a largura dessas seções transversais enquadrou-se, respectivamente, entre os intervalos de $\leq 3 \mathrm{~m}$, de 3 a $6 \mathrm{~m}$, e, 6 a 15m, durante o período de abril a outubro de 2019. Com relação à profundidade da vertical, quando esta ultrapassou $0,60 \mathrm{~m}$ foi necessário realizar a média da velocidade de fluxo considerando dois pontos, sendo um $20 \%$ e outro $80 \%$ da profundidade da vertical a contar da lâmina d'água. Todas as medições das velocidades de fluxo em cada vertical, considerando a seção transversal do rio das oito sub-bacias hidrográficas, foram aferidas até o momento de estabilização dos valores no molinete hidrométrico.

Após a coleta dos dados por meio das ferramentas do software AutoCAD ${ }^{\circledR}$ foi elaborado o perfil transversal próximo ao exutório de cada uma das sub-bacias hidrográficas considerando o período entre os meses de abril a outubro do ano de 2019. Tal procedimento permitiu a obtenção da área da seção transversal nos locais em que foram realizadas as medições de velocidade de fluxo nas oito sub-bacias hidrográficas, deste modo foi possível a determinação das vazões. Vale ressaltar que as medições de velocidade de fluxo foram realizadas também no fim de cada mês analisado, de forma a considerar períodos secos e chuvosos.

Em seguida, foram correlacionados os valores obtidos da precipitação e da vazão, a fim de analisar de forma pormenorizada o comportamento hidrológico de cada par das sub-bacias hidrográficas em estudo no período analisado.

\section{RESULTADOS}

A BHRP apresenta 180 sub-bacias hidrográficas de $4^{\underline{a}}$ ordem de ramificação, que abrangem uma extensão territorial que varia entre $2,89 \mathrm{~km}^{2}$ a $304,07 \mathrm{~km}^{2}$. A análise do dendrograma apresenta a formação de 45 grupos de sub-bacias hidrográficas, sendo que 50 sub-bacias hidrográficas não se enquadram em nenhum grupo, denominadas anômalas quanto aos parâmetros que foram analisados, pois apresentam alta heterogeneidade em relação à área, densidade de drenagem, densidade hidrográfica e índice de circularidade (Figura 4).

Deste total de grupos, foram escolhidos 4 , sendo que cada um destes é representado por um par de sub-bacias hidrográficas. A escolha dos 4 pares selecionados se justifica por estarem bem distribuídos por toda a área de abrangência da BHRP, o que caracteriza um fator positivo para entender a dinâmica de toda área, que se diferencia morfometricamente nas porções oeste e leste, em função da variabilidade geomorfológica da BHRP. 
A Tabela 2 apresenta os valores dos índices morfométricos dos pares de sub-bacias hidrográficas escolhidas.

Tabela 2 - Dados quantitativos dos pares de sub-bacias hidrográficas de $4^{\underline{a}}$ ordem.

\begin{tabular}{c|c|c|c|c|c}
\hline Pares & \multicolumn{1}{c}{ Sub-Bacias Hidrográficas } & \multicolumn{1}{c}{ A* $^{*}$} & Dd* & Dh* & \multicolumn{1}{c}{ Ic* $^{*}$} \\
\hline \multirow{2}{*}{1} & A - Sub-bacia Hidrográfica do Rio da Prata & 98,71 & 1,60 & 1,34 & 0,46 \\
\cline { 2 - 6 } & B - Sub-bacia Hidrográfica do Ribeirão das Taparanas & 98,42 & 1,38 & 1,06 & 0,39 \\
\hline \multirow{2}{*}{2} & C - Sub-bacia Hidrográfica do Ribeirão da Cachoeira & 116,27 & 0,79 & 0,22 & 0,43 \\
\cline { 2 - 6 } & D - Sub-bacia Hidrográfica do Córrego dos Coqueiros & 115,56 & 0,91 & 0,44 & 0,55 \\
\hline \multirow{2}{*}{3} & E - Sub-bacia Hidrográfica do Córrego das Onças & 20,37 & 2,35 & 2,21 & 0,45 \\
\cline { 2 - 6 } & F - Sub-bacia Hidrográfica do Afluente do Ribeirão Jacaré & 19,83 & 2,42 & 2,37 & 0,47 \\
\hline \multirow{2}{*}{4} & G - Sub-bacia Hidrográfica do Ribeirão da Folha Larga & 10,96 & 2,86 & 3,29 & 0,57 \\
\cline { 2 - 6 } & H - Sub-bacia Hidrográfica do Ribeirão Boa Morte & 10,53 & 3,08 & 3,33 & 0,51 \\
\hline
\end{tabular}

*A: Área $\left(\mathbf{k m}^{2}\right)$ Dd: Densidade de drenagem $\left(\mathbf{k m} / \mathbf{k m}^{2}\right)$ Dh: Densidade hidrográfica (canais/km²) Ic: Índice de circularidade

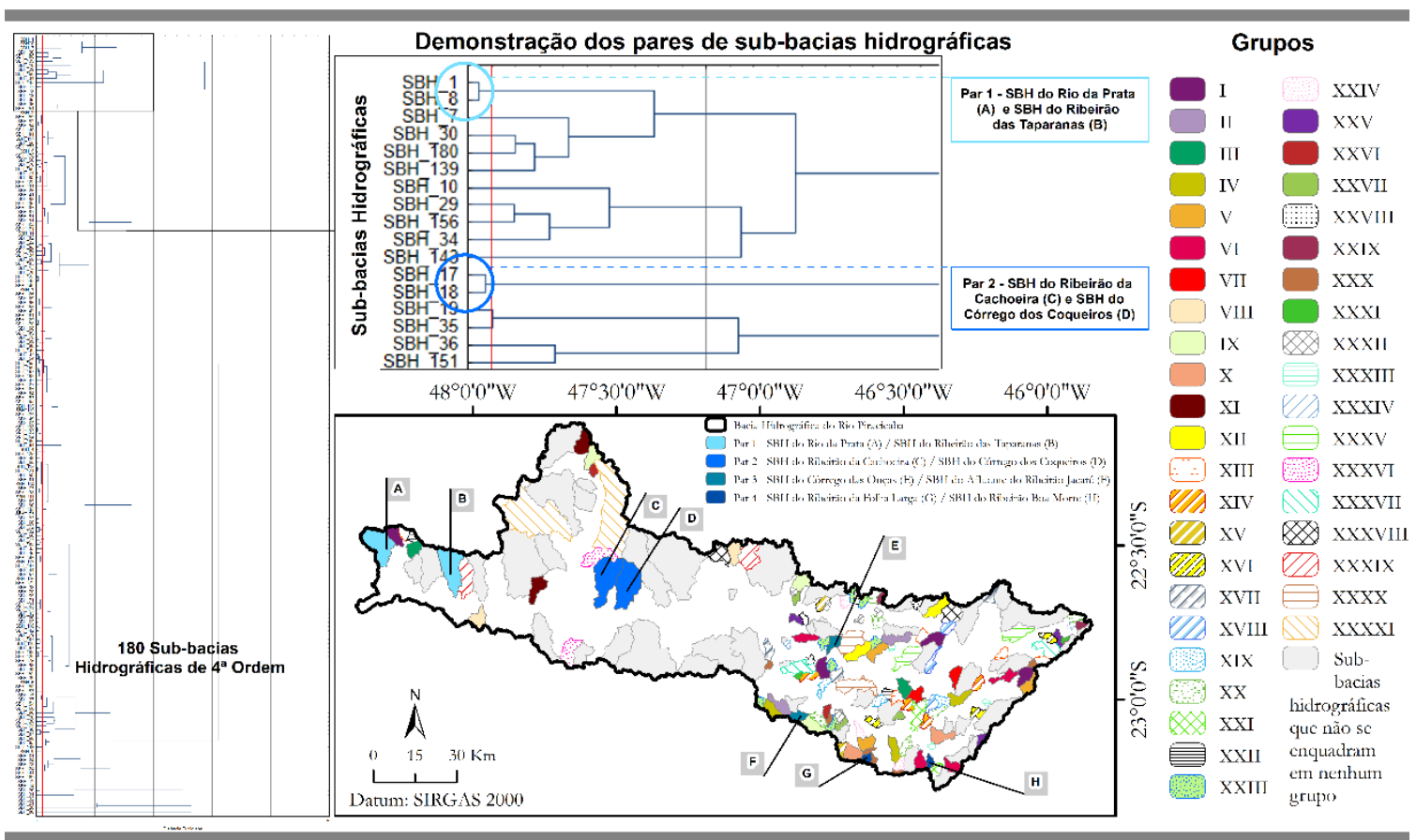

Figura 4 - Dendrograma após a análise de agrupamento utilizando os índices morfométricos.

A Figura 5 apresenta as sub-bacias hidrográficas de $4^{\text {a }}$ ordem da BHRP, bem como, a espacialização dos quatro pares de sub-bacias hidrográficas. Ressalta-se que a escolha destes pares levou em consideração também a posição geográfica das sub-bacias hidrográficas, optando-se desta forma, para a escolha de pares nas extremidades e nas porções centrais da BHRP. 


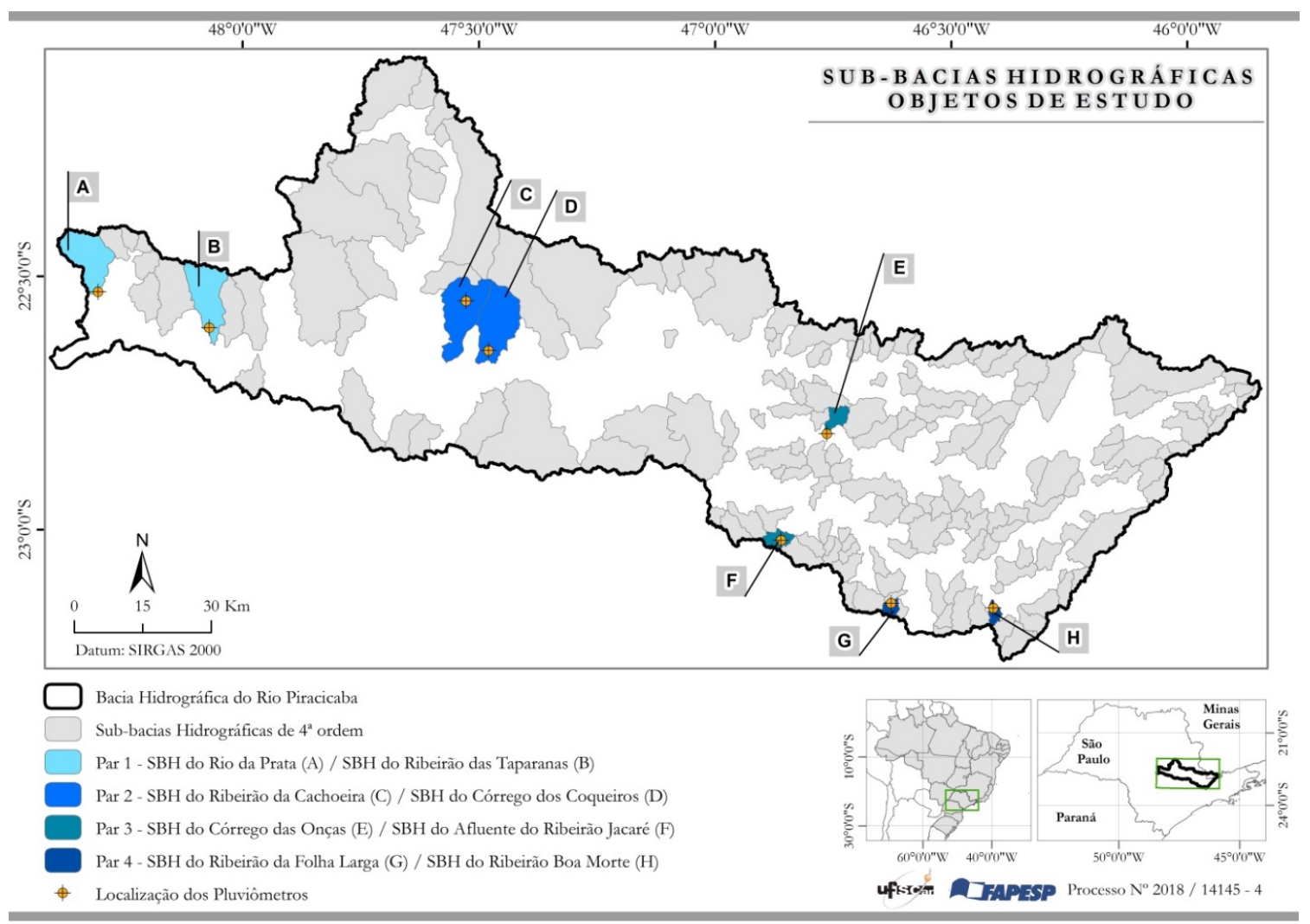

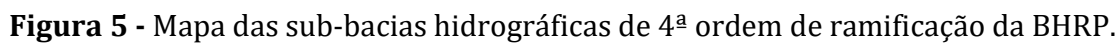

Os quatro pares apresentam similaridade quanto aos padrões morfométricos analisados, uma das características que destacam a semelhança remete-se ao formato mais alongado das sub-bacias hidrográficas, com índice de circularidade variando entre 0,39 a 0,57. Tal condição se configura com menor tempo de concentração de água nos seus limites, pois os afluentes atingem o rio principal em diversos pontos ao longo de sua extensão. A tendência destas sub-bacias hidrográficas é apresentar cheias distribuídas, com menor vazão de pico (Villela \& Mattos, 1975).

As sub-bacias hidrográficas pertencentes aos pares 1 e 2 com extensões territoriais maiores, localizadas na região oeste da BHRP apresentam densidade de drenagem classificada como regular a boa, pois o índice varia de 0,91 a $1,60 \mathrm{~km} / \mathrm{km}^{2}$, o que representa que estas áreas possuem maior potencial para infiltração. Enquanto que nos pares 3 e 4 situados a leste da BHRP, a densidade de drenagem caracteriza-se como boa a muito boa, por apresentar valores entre 2,35 a 3,08 km/ $\mathrm{km}^{2}$, estas áreas apresentam maior capacidade de escoar rapidamente o fluxo de água ao exutório (Villela \& Mattos, 1975). A maior densidade de drenagem nas sub-bacias hidrográficas que compõem os pares 3 e 4 é compreendida por estas áreas estarem situadas em terrenos acidentados o que não favorece o processo de infiltração, permitindo obter uma maior ramificação da rede de drenagem.

Quanto à densidade hidrográfica, o par 2 apresentou o menor valor, ou seja, não atinge 1,0 canal por $\mathrm{km}^{2}$. Com relação ao par 1, este também apresenta baixa densidade hidrográfica, no entanto as suas sub-bacias abrangem pouco mais de 1,0 canal por $\mathrm{km}^{2}$. A maior densidade hidrográfica ocorre nos pares 3 e 4, variando de 2,21 a 3,33 canais por $\mathrm{km}^{2}$, estas áreas representam maior aptidão ao aparecimento de pequenos canais de drenagem, que podem contribuir de forma pontual e discreta na disponibilidade hídrica superficial.

A diferença nos padrões de drenagem dos pares refere-se às características geomorfológicas e físicas das sub-bacias hidrográficas.

As sub-bacias hidrográficas estudadas que compõem cada par apresentam pouca variação de área (inferior a 4,2\%), no entanto somente a área não é um atributo suficiente para determinar o comportamento hídrico de áreas de drenagem, visto que, duas sub-bacias hidrográficas com tamanhos quase idênticos, podem não garantir a mesma condição hidrológica. A chuva se caracteriza como agente ativo que pode corroborar para tal situação, não menos importantes os agentes passivos também atuam na dinâmica hídrica por estarem associados às características físicas e antrópicas da determinada área. A Figura 6 apresenta as vazões específicas $\left(\mathrm{m}^{3} / \mathrm{s} / \mathrm{km}^{2}\right)$ para cada par de sub-bacias hidrográficas, o que retrata que a extensão territorial semelhante entre cada par não garante a mesma vazão. 


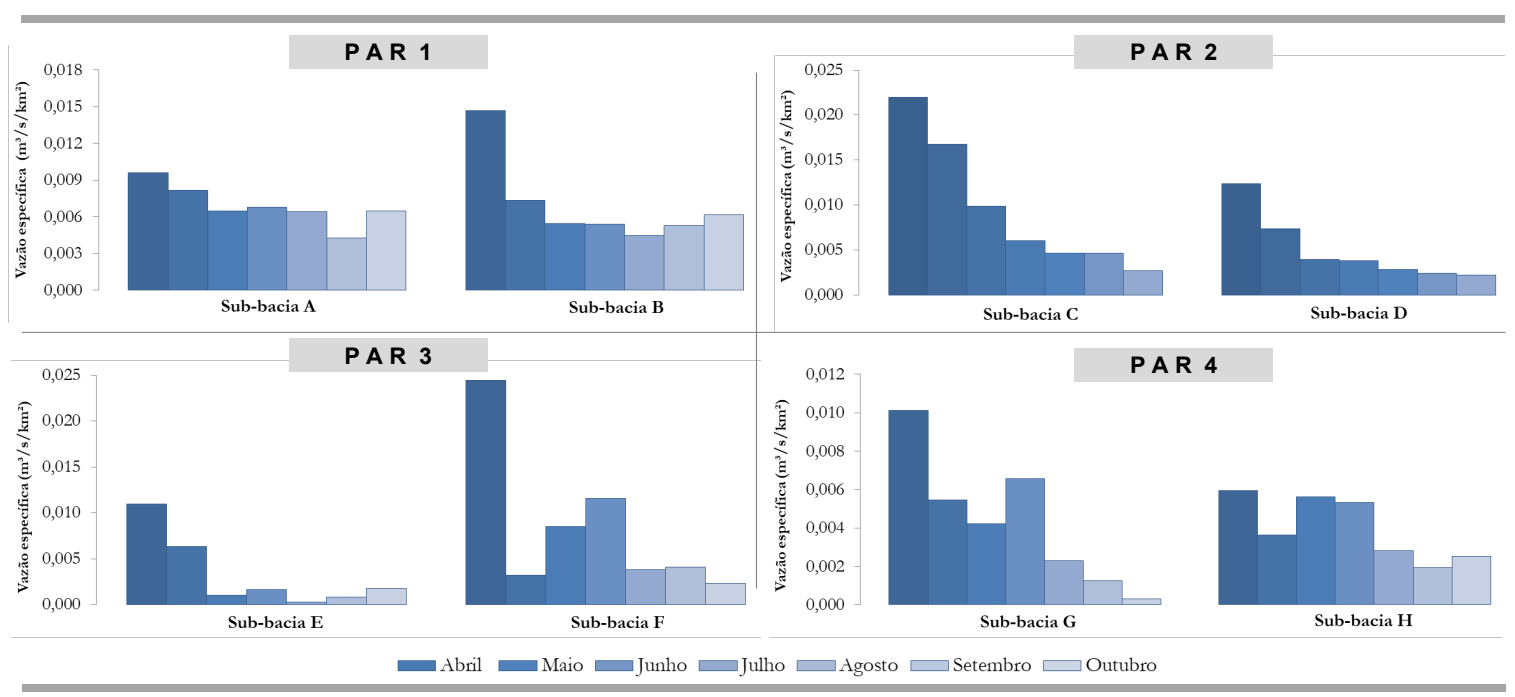

Figura 6 - Vazão específica de cada par de sub-bacias hidrográficas.

A Tabela 3 apresenta a largura (m) e a área da seção transversal do rio $\left(\mathrm{m}^{2}\right)$, a média da velocidade de fluxo $(\mathrm{m} / \mathrm{s})$, a vazão $\left(\mathrm{m}^{3} / \mathrm{s}\right)$ obtida por meio do método de batimetria e a pluviosidade $(\mathrm{mm})$, aferidas nas sub-bacias hidrográficas entre os meses de abril a outubro de 2019.

Tabela 3 - Valores de velocidade de fluxo, vazão medida in situ e pluviosidade nas sub-bacias hidrográficas objetos de estudo.

\begin{tabular}{|c|c|c|c|c|c|c|}
\hline SBH & $\begin{array}{l}\text { Dia e Mês da } \\
\text { medição de } \\
\text { vazão e } \\
\text { pluviosidade* }\end{array}$ & $\begin{array}{c}\text { Largura da } \\
\text { seção } \\
\text { transversal } \\
\text { do rio (m) }\end{array}$ & $\begin{array}{c}\text { Área da } \\
\text { seção }\left(\mathrm{m}^{2}\right)\end{array}$ & $\begin{array}{c}\text { Média da } \\
\text { velocidade } \\
\text { de fluxo } \\
\text { (m/s) }\end{array}$ & $\begin{array}{l}\text { Vazão } \\
\left(m^{3} / s\right)\end{array}$ & $\begin{array}{l}\text { Pluviosidade } \\
\text { (mm) }\end{array}$ \\
\hline \multirow{7}{*}{$\begin{array}{l}\text { A - SBH do } \\
\text { Rio Prata }\end{array}$} & 11/04-Abril & 8,40 & 3,057 & 0,310 & 0,948 & 141,40 \\
\hline & 31/05-Maio & 6,00 & 2,335 & 0,346 & 0,808 & 21,10 \\
\hline & 01/07-Junho & 5,90 & 1,930 & 0,331 & 0,638 & 13,00 \\
\hline & 30/07-Julho & 6,40 & 2,000 & 0,336 & 0,671 & 11,70 \\
\hline & 29/08-Agosto & 6,40 & 1,883 & 0,336 & 0,632 & 4,50 \\
\hline & 30/09-Setembro & 6,10 & 1,644 & 0,257 & 0,423 & 105,30 \\
\hline & 30/10-Outubro & 5,10 & 1,939 & 0,329 & 0,638 & 103,90 \\
\hline \multirow{7}{*}{$\begin{array}{l}\text { B - SBH do } \\
\text { Ribeirão } \\
\text { das } \\
\text { Taparanas }\end{array}$} & 11/04-Abril & 5,80 & 3,297 & 0,438 & 1,446 & 144,70 \\
\hline & 31/05-Maio & 4,90 & 2,406 & 0,300 & 0,722 & 58,40 \\
\hline & 01/07-Junho & 4,70 & 1,905 & 0,282 & 0,537 & 23,40 \\
\hline & 30/07-Julho & 4,80 & 2,283 & 0,232 & 0,529 & 58,00 \\
\hline & 29/08-Agosto & 4,70 & 2,020 & 0,218 & 0,441 & 6,30 \\
\hline & 30/09-Setembro & 4,70 & 2,082 & 0,250 & 0,521 & 57,60 \\
\hline & 30/10-Outubro & 5,10 & 2,437 & 0,250 & 0,609 & 70,20 \\
\hline \multirow{7}{*}{$\begin{array}{c}\text { C - SBH do } \\
\text { Ribeirão da } \\
\text { Cachoeira }\end{array}$} & 24/04-Abril & 6,00 & 2,765 & 0,923 & 2,552 & 172,60 \\
\hline & 31/05-Maio & 5,10 & 2,145 & 0,908 & 1,948 & 25,20 \\
\hline & 01/07-Junho & 5,00 & 1,635 & 0,700 & 1,145 & 22,50 \\
\hline & 30/07-Julho & 4,90 & 1,140 & 0,618 & 0,704 & 32,80 \\
\hline & 29/08-Agosto & 4,90 & 1,037 & 0,518 & 0,537 & 0,40 \\
\hline & 30/09-Setembro & 4,90 & 1,032 & 0,527 & 0,544 & 36,40 \\
\hline & 30/10-Outubro & 4,70 & 0,863 & 0,364 & 0,314 & 56,20 \\
\hline
\end{tabular}


Tabela 3 - Continuação...

\begin{tabular}{|c|c|c|c|c|c|c|}
\hline SBH & $\begin{array}{l}\text { Dia e Mês da } \\
\text { medição de } \\
\text { vazão e } \\
\text { pluviosidade* }\end{array}$ & $\begin{array}{l}\text { Largura da } \\
\text { seção } \\
\text { transversal } \\
\text { do rio (m) }\end{array}$ & $\begin{array}{c}\text { Área da } \\
\text { seção }\left(\mathrm{m}^{2}\right)\end{array}$ & $\begin{array}{c}\text { Média da } \\
\text { velocidade } \\
\text { de fluxo } \\
\text { (m/s) }\end{array}$ & $\begin{array}{l}\text { Vazão } \\
\left(\mathrm{m}^{3} / \mathrm{s}\right)\end{array}$ & $\begin{array}{l}\text { Pluviosidade } \\
\text { (mm) }\end{array}$ \\
\hline \multirow{7}{*}{$\begin{array}{l}\text { D - SBH do } \\
\text { Córrego } \\
\text { dos } \\
\text { Coqueiros }\end{array}$} & 17/04-Abril & 5,24 & 2,019 & 0,709 & 1,432 & 163,90 \\
\hline & 31/05-Maio & 4,70 & 1,393 & 0,609 & 0,848 & 30,10 \\
\hline & 01/07-Junho & 4,50 & 0,993 & 0,460 & 0,457 & 19,80 \\
\hline & 30/07-Julho & 4,40 & 0,983 & 0,450 & 0,442 & 48,60 \\
\hline & 29/08-Agosto & 4,30 & 0,854 & 0,380 & 0,324 & 4,50 \\
\hline & 30/09-Setembro & 4,30 & 0,865 & 0,320 & 0,277 & 42,70 \\
\hline & 30/10-Outubro & 4,25 & 0,783 & 0,320 & 0,250 & 48,10 \\
\hline \multirow{7}{*}{$\begin{array}{c}\text { E - SBH do } \\
\text { Ribeirão } \\
\text { das Onças }\end{array}$} & 16/04-Abril & 4,18 & 1,176 & 0,190 & 0,223 & 148,30 \\
\hline & 31/05-Maio & 4,40 & 0,517 & 0,250 & 0,129 & 20,70 \\
\hline & 02/07-Junho & 3,80 & 0,973 & 0,022 & 0,022 & 0,00 \\
\hline & 31/07-Julho & 3,90 & 0,997 & 0,033 & 0,033 & 104,80 \\
\hline & 30/08-Agosto & 3,80 & 0,536 & 0,011 & 0,006 & 58,90 \\
\hline & 01/10-Setembro & 3,70 & 0,787 & 0,022 & 0,017 & 83,70 \\
\hline & 31/10-Outubro & 4,10 & 0,905 & 0,040 & 0,036 & 22,40 \\
\hline \multirow{7}{*}{$\begin{array}{c}\text { F - SBH do } \\
\text { Afluente do } \\
\text { Ribeirão } \\
\text { Jacaré }\end{array}$} & 16/04-Abril & 4,40 & 0,949 & 0,510 & 0,484 & 114,80 \\
\hline & 31/05-Maio & 4,18 & 0,795 & 0,080 & 0,064 & 36,80 \\
\hline & 02/07-Junho & 4,50 & 0,888 & 0,190 & 0,169 & 22,00 \\
\hline & 31/07-Julho & 4,80 & 0,969 & 0,236 & 0,229 & 90,00 \\
\hline & 30/08-Agosto & 4,20 & 0,541 & 0,140 & 0,076 & 6,30 \\
\hline & 01/10-Setembro & 4,10 & 0,542 & 0,150 & 0,081 & 36,90 \\
\hline & 31/10-Outubro & 4,10 & 0,417 & 0,110 & 0,046 & 21,10 \\
\hline \multirow{7}{*}{$\begin{array}{c}\text { G - SBH do } \\
\text { Ribeirão da } \\
\text { Folha Larga }\end{array}$} & 23/04-Abril & 1,70 & 0,554 & 0,200 & 0,111 & 108,40 \\
\hline & 31/05-Maio & 1,60 & 0,419 & 0,143 & 0,060 & 57,50 \\
\hline & 02/07-Junho & 1,60 & 0,462 & 0,100 & 0,046 & 59,40 \\
\hline & 31/07-Julho & 1,70 & 0,459 & 0,157 & 0,072 & 130,00 \\
\hline & 30/08-Agosto & 1,80 & 0,350 & 0,071 & 0,025 & 7,20 \\
\hline & 01/10-Setembro & 1,75 & 0,321 & 0,043 & 0,014 & 43,20 \\
\hline & 31/10-Outubro & 1,70 & 0,234 & 0,014 & 0,003 & 49,50 \\
\hline \multirow{7}{*}{$\begin{array}{l}\text { H - SBH do } \\
\text { Ribeirão } \\
\text { Boa Morte }\end{array}$} & 24/04-Abril & 2,80 & 1,147 & 0,055 & 0,063 & 114,60 \\
\hline & 31/05-Maio & 2,80 & 1,051 & 0,036 & 0,038 & 69,70 \\
\hline & 02/07-Junho & 2,50 & 0,984 & 0,060 & 0,059 & 80,50 \\
\hline & 31/07-Julho & 2,50 & 1,121 & 0,050 & 0,056 & 133,60 \\
\hline & 30/08-Agosto & 2,50 & 0,982 & 0,030 & 0,029 & 13,00 \\
\hline & 01/10-Setembro & 2,70 & 1,022 & 0,020 & 0,020 & 54,40 \\
\hline & 31/10-Outubro & 2,75 & 0,968 & 0,027 & 0,026 & 32,80 \\
\hline
\end{tabular}

* Os valores de precipitação no mês de abril foram adquiridos por meio do Centro Integrado de Informações Agrometeorológicas, devido ter sido o mês de instalação dos pluviômetros.

A Figura 7 apresenta a relação das variáveis hidrológicas abordadas neste trabalho, considerando cada par das sub-bacias hidrográficas objetos de estudo. 


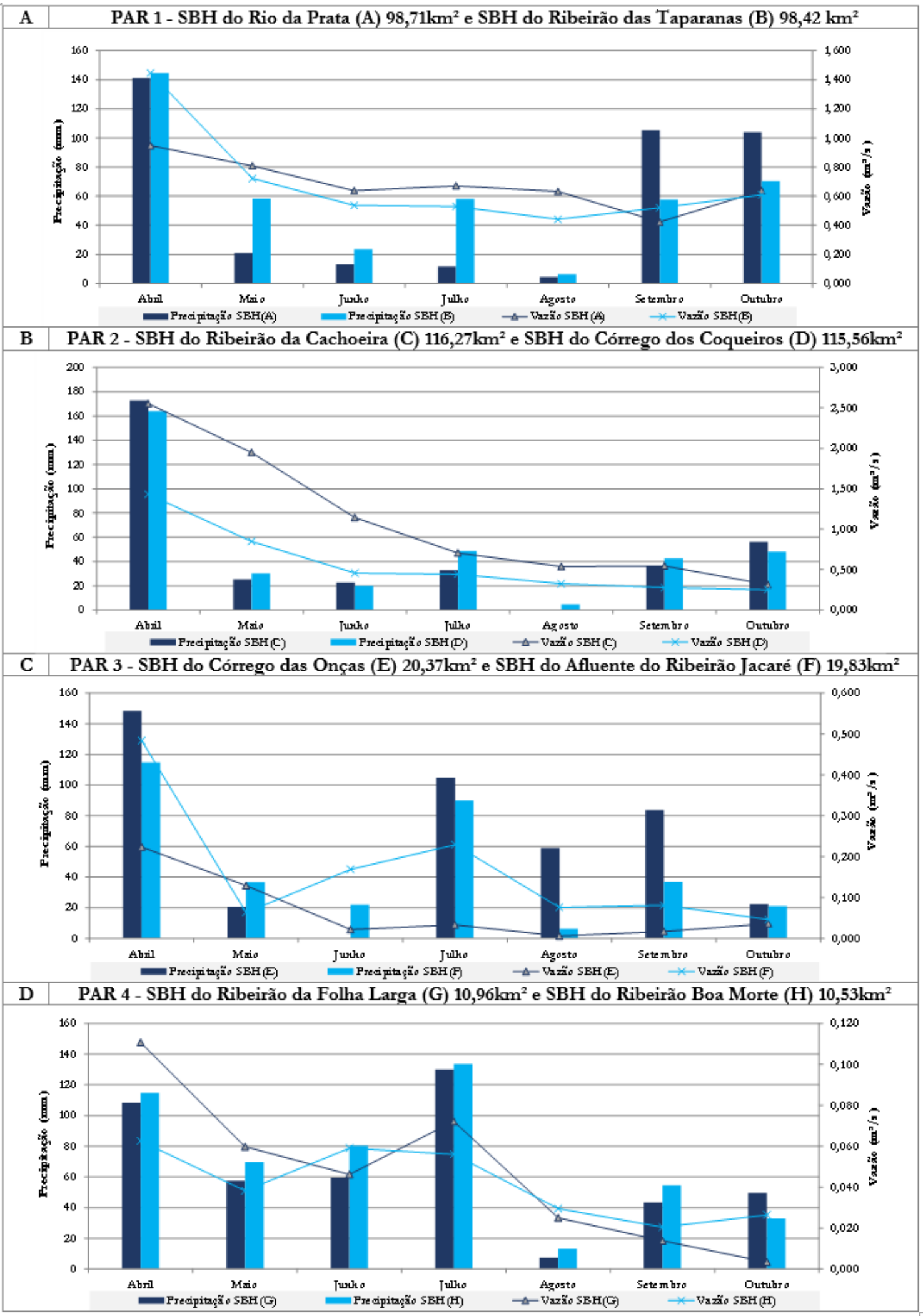

Figura 7 - Relação das variáveis hidrológicas das sub-bacias hidrográficas objetos de estudo.

A proposta metodológica para a escolha das áreas de drenagem amostrais permitiu a obtenção de pares de sub-bacias hidrográficas que apresentam similaridade morfométrica, como mencionado anteriormente. Isso pode ser constatado com a semelhança da extensão territorial e do sistema de drenagem dessas áreas. 
Embora os pares de sub-bacias hidrográficas sejam morfometricamente similares, verificou-se diferenças no comportamento hidrológico nos Pares 1, 2 e 3, com base na precipitação e vazão, isso pode ser caracterizado pela distribuição, intensidade de chuvas, data de ocorrência do evento nos meses analisados.

A seguir são descritas a relação da chuva e vazão nos pares de sub-bacias hidrográficas:

PAR 1 - SBH do Rio da Prata (A) e SBH do Ribeirão das Taparanas (B): o mês de abril (assim como nos demais pares de sub-bacias hidrográficas em estudo) se destaca com o volume precipitado superior aos outros meses, mesmo após o final da estação chuvosa. Neste mesmo mês, ambas sub-bacias hidrográficas apresentaram semelhança quanto à quantidade de chuva, que corresponde 141,40mm para a SBH (A) e 144,70mm para a SBH (B), no entanto, não apresentaram efeito direto nas vazões. Entre os meses de maio a agosto, percebe-se nitidamente o declínio de chuvas, ou seja, refere-se ao período de estiagem, porém, o evento teve maior ocorrência na SBH (B), e mesmo ocorrendo precipitações menores na SBH (A), as vazões permaneceram praticamente constantes e mais elevadas do que na SBH (B). A precipitação nos meses de setembro e outubro não evidenciou diferenças expressivas para a SBH (A), enquanto que, para SBH (B) houve oscilação na ordem de $12,6 \mathrm{~mm}$. No mês de setembro, a SBH (A) apresentou um nível de vazão mais baixo quando comparada com a vazão da SBH (B), mesmo tendo ocorrido um maior volume de precipitação, tal situação pode ser proveniente do aumento de volume de água captado nesta sub-bacia hidrográfica.

As chuvas diferentes ocorreram entre os meses de maio a agosto (período de estiagem), como o solo não se encontra saturado neste período, possivelmente parte do volume precipitado sofreu influência do processo de infiltração da água na camada superficial do solo, além da ação do escoamento e da evaporação. Ressalta-se que no período de estiagem as vazões tendem a variar menos, mesmo com eventos chuvosos isolados.

A ocorrência dos eventos de chuva na SBH (A) pode ter sido de intensidade moderada, distribuída ao mês e também não próxima ao final de cada mês (momento da medição da velocidade de fluxo), dessa forma não interferiu diretamente na vazão aferida, constatando assim que em ambas sub-bacias hidrográficas as vazões permanecem similares.

PAR 2 - SBH do Ribeirão da Cachoeira (C) e SBH do Córrego dos Coqueiros (D): verifica-se que houve um decréscimo das vazões das sub-bacias hidrográficas no período de abril a outubro. Quando comparado o período de abril a julho nestas duas áreas, certifica-se que houve uma assimetria dos valores de vazão, isto pode ser explicado devido à ocorrência de intervenções antrópicas que exercem pressões diferentes nas áreas estudadas, afetando diretamente a oferta hídrica. Uma das atividades antrópicas consiste na demanda da água para pulverização da cultura de citrus na SBH (D), enquanto que na SBH (C), maior parte da sua área é ocupada por cana-de-açúcar, que depende do uso da água no seu estágio de plantio com a adoção da fertirrigação. Além disso, esse fato pode estar associado à distribuição de chuvas ao longo do mês.

Ressalta-se que o volume de água precipitado foi o menor no mês de agosto, compreendendo $0,4 \mathrm{~mm}$ na SBH (C), enquanto que na SBH (D) não ultrapassou $5 \mathrm{~mm}$ ao mês. No período de agosto a outubro, a vazão na SBH (D) manteve-se estável, entretanto, a vazão na SBH (C) permaneceu constante entre os meses de agosto a setembro, decaindo no mês de outubro, mesmo sendo o segundo mês que apresentou maior volume precipitado quando comparadas simultaneamente as duas áreas.

PAR 3 - SBH do Ribeirão das Onças (E) e SBH do Afluente do Ribeirão Jacaré (F): exceto o mês de outubro, o período analisado demonstrou alteração nas vazões de ambas sub-bacias hidrográficas. Evidencia-se que no mês de junho não houve ocorrência de precipitação na SBH (E), enquanto que para a SBH (F) a precipitação mensal totalizou $22 \mathrm{~mm}$, em consequência houve um aumento na vazão quando comparado com o mês anterior nesta mesma área. No período de estiagem, o mês de julho se destacou no volume precipitado, correspondendo 104,80mm na SBH (E) e 90,00mm na SBH (F), na qual refletiu o aumento da vazão, o que não ocorreu na SBH (E). Tal fato se repete nos meses de agosto, setembro e outubro.

As diferenças entre as vazões das sub-bacias hidrográficas do par 3 podem estar associadas às unidades geológicas predominantes. A SBH (E) apresenta maior ocorrência de Granitoides Indiferenciados, especialmente nas áreas de menores declividades, a alteração deste tipo litológico dá origem a materiais inconsolidados residuais de textura arenosa e baixa compacidade. Na SBH (F) predominam Biotita-Gnaisses, cuja alteração resultam solos com textura mais fina (siltosa e argilosa), de consistência média. Tais características de substrato rochoso e perfis de solos em áreas com menor inclinação do terreno na SBH (E) favorecem o processo de infiltração, quando comparada com a SBH (F), e essa situação pode explicar as menores vazões, mesmo apresentando as maiores precipitações na SBH (E). 
PAR 4 - SBH do Ribeirão da Folha Larga (G) e SBH do Ribeirão Boa Morte (H): dentre os pares de sub-bacias hidrográficas objetos de estudo, o par 4 se destacou em volume precipitado nos meses de abril a julho, os quais se enquadram no período seco do ano, no entanto, as vazões no canal principal destas áreas neste mesmo período apresentam os valores mais baixos, tal situação pode ter influência da exploração dos recursos hídricos nestas sub-bacias hidrográficas. A partir do mês de julho, ocorreu um declínio da precipitação, que consequentemente resultou na diminuição da vazão de ambas as áreas. Um ponto importante observado refere-se que no mês de julho (período seco) houve maior precipitação, quando comparado com os outros meses analisados.

Este par se destacou por apresentar maior semelhança nos valores de pluviosidade e vazão entre as sub-bacias hidrográficas que o compõem. Além da morfometria semelhante, essas duas sub-bacias hidrográficas (G e H) estão situadas em regiões com características do meio físico (solo, geomorfologia, hipsometria, declividade) que apresentam maior similaridade.

\section{CONCLUSÃO}

A escolha das sub-bacias hidrográficas objetos de estudo, por meio de análise estatística hierárquica multivariada permitiu o estabelecimento de áreas semelhantes quanto aos parâmetros morfométricos para fins do estudo hidrológico. Desta forma, o critério de análise por pares de sub-bacias hidrográficas proporcionou identificar as relações das variáveis hidrológicas de forma integrada, considerando as especificidades físicas que compõem cada par.

A utilização dos dados de vazão dos cursos d'água principais das sub-bacias hidrográficas mostrou-se adequado para a finalidade do estudo, podendo ser aplicado em bacias hidrográficas de pequeno porte, bem como o monitoramento pluviométrico foi importante para adquirir dados específicos considerando os limites das áreas estudadas, de maneira que os equipamentos foram instalados em cada uma das sub-bacias hidrográficas objetos de estudo.

A análise de correlação por pares das sub-bacias hidrográficas, considerando a precipitação e a vazão, permitiu a obtenção de um diagnóstico preliminar referente ao comportamento hidrológico das áreas, evidenciando que outros fatores, além da morfometria e das precipitações, podem estar influenciando na vazão retratada no exutório. As constatadas variações entre os valores de vazão para algum mês analisado em cada par de sub-bacias hidrográficas podem estar relacionadas a fatores antrópicos como o uso e cobertura do solo, o uso da água, ou fatores físicos. Para uma análise mais detalhada do comportamento hidrológico de áreas de drenagem similares, a análise integrada de atributos do meio físico (declividade, materiais inconsolidados, geologia) e antrópico (uso e cobertura do solo, demanda de captações superficiais e subterrâneas) poderá indicar a influência direta ou indireta que estes atributos exercem sobre a vazão.

\section{AGRADECIMENTOS}

Os autores agradecem a Fundação de Amparo à Pesquisa do Estado de São Paulo (FAPESP), pela concessão de recursos financeiros, aportados ao Processo no. 2018/14145-4, os quais possibilitaram a elaboração dos resultados deste trabalho e informam que "o presente trabalho foi realizado com apoio da Coordenação de Aperfeiçoamento de Pessoal de Nível Superior - Brasil (CAPES) - Código de Financiamento 001".

\section{REFERÊNCIAS BIBLIOGRÁFICAS}

Agência das Bacias PCJ. (2018) Primeira Revisão do Plano das Bacias Hidrográficas dos Rios Piracicaba, Capivari e Jundiaí para o período de 2010 a 2020. Relatório Final. Tomo IV - Plano de Ações. Piracicaba. 201 p.

Agência Nacional de Águas - ANA. (2019) Manual de usos consuntivos da Água no Brasil. Brasília: Agência Nacional de Águas. $75 \mathrm{p}$.

Burek, P., Satoh, Y., Fischer, G., Kahil, M. T., Scherzer, A., Tramberend, S., Nava, L. F., Wada, Y., Eisner, S., Flörke, M., Hanasaki, N., Magnuszewski, P., Cosgrove, B., \& Wiberg, D. (2016). Water Futures and Solution - Fast Track Initiative (Final Report) (IIASA Working Paper, vol. 11). Laxenburg, Austria: IIASA.

Centro Integrado de Informações Agrometeorológicas - CIIAGRO. (2019) Monitoramento Climatológico. Recuperado em 12 de novembro de 2019, de http://www.ciiagro.sp.gov.br/

Companhia Brasileira de Projetos e Empreendimentos - COBRAPE. (2010) Relatório Final - Plano das Bacias Hidrográficas dos Rios Piracicaba, Capivari e Jundiaí 2010-2020, com Propostas de Atualização do 
Enquadramento dos Corpos d'Água e de Programa para Efetivação do Enquadramento dos Corpos d'Água até o Ano de 2035. p. 788.

Dirección General de Aguas - DGA (1991). Manual básico para instruccion de hidromensores. Santiago, Chile: DGA. 408p.

Engenharia e Consultoria em Recursos Hídricos e Meio Ambiente Ltda - IRRIGART. (2007) Relatório de Situação dos Recursos Hídricos das Bacias Hidrográficas dos Rios Piracicaba, Capivari e Jundiaí. Piracicaba - 2004 a 2006. Piracicaba: FEHIDRO/PCJ/CBJPCJ.

Gaucherel, C., Frelat, R., Salomon, L., Rouy, B., Pandey, N., \& Cudennec, C. (2017). Regional watershed characterization and classification with river network analyses. Earth Surface Processes and Landforms, 42(13), 2068-2081.

Horton, R. E. (1945). Erosional development of streams and their drainage basins: hydrophysical approach to quantitative morphology. Geological Society of America Bulletin, 56(3), 275-370.

Instituto Brasileiro de Geografia e Estatística - IBGE. (2019) Curvas de Nível e Pontos Cotados. Rio de Janeiro: IBGE. Recuperado em 10 de novembro de 2019, de https://loja.ibge.gov.br/

Jaramillo, P., \& Nazemi, A. (2018). Assessing urban water security under changing climate: challenges and ways forward. Sustainable Cities and Society, 41, 907-918.

Jodar-Abellan, A., Fernández-Aracil, P., \& Melgarejo-Moreno, J. (2019). Assessing water shortage through a balance model among transfers, groundwater, desalination, wastewater reuse, andwater demands (SE spain). Water (Switzerland), 11(5), 1-18.

Kaewmai, R., Grant, T., Eady, S., Mungkalasiri, J., \& Musikavong, C. (2019). Improving regional water scarcity footprint characterization factors of an available water remaining (AWARE) method. The Science of the Total Environment, 681, 444-455.

Karlsen, R. H., Seibert, J., Grabs, T., Laudon, H., Blomkvist, P., \& Bishop, K. (2016). The assumption of uniform specific discharge: unsafe at any time? Hydrological Processes, 30(21), 3978-3988.

Lakshmi, V., Fayne, J., \& Bolten, J. (2018). A comparative study of available water in the major river basins of the world. Journal of Hydrology (Amsterdam), 567, 510-532.

Landim, P. M. B. (2011). Análise Estatística de Dados Geológicos Multivariados. São Paulo, SP: Oficina de Textos. $208 \mathrm{p}$.

Makarigakis, A. K., \& Jimenez-Cisneros, B. E. (2019). UNESCO's contribution to face global water challenges. Water (Switzerland), 11(2), 1-17.

Mapbiomas Brasil. (2018) Mapa de Uso e Cobertura do Solo do ano de 2018. Recuperado em 17 de abril de 2020, de https://mapbiomas.org/colecoes-mapbiomas-1?cama_set_language=pt-BR.

Mekonnen, M. M., \& Hoekstra, A. Y. (2016). Sustainability: Four billion people facing severe water scarcity. Science Advances, 2(2), 1-6.

Miller, V. C. (1953). A quantitative geomorphology study of drainage basin characteristic in the Clinch Mountain Area Virginia and Tennesse. New York: Columbia University. 30 p.

Oki, T., \& Kanae, S. (2006). Global hydrological cycles and world water resources. Science, 313(5790), 10681072.

Sala, O. E., Gherardi, L. A., \& Peters, D. P. C. (2015). Enhanced precipitation variability effects on water losses and ecosystem functioning: differential response of arid and mesic regions. Climatic Change, 131(2), 213-227.

Santos, I., Fill, H. D., Sugai, M. R. V. B., Buba, H., Kishi, R. T., Marone, E., \& Lautert, L. F. (2001). Hidrometria aplicada. Curitiba, PR: Instituto de Tecnologia para o Desenvolvimento, LACTEC. 372 p.

São Paulo SICCT-PROMOCET-IPT. (1981) Mapa Geológico do Estado de São Paulo. São Paulo: Secretaria da Indústria, Comércio, Ciência e Tecnologia. PROMOCET - Companhia de Promoção de Pesquisa Científica e Tecnológica do Estado de São Paulo. IPT - Instituto de Pesquisas Tecnológicas do Estado de São Paulo. Mapa escala 1:500.000, São Paulo : Instituto de Pesquisas Tecnológicas do Estado de São Paulo.

Strahler, A. N. (1957). Quantitative analysis of watershed geomorphology. Eos, Transactions American Geophysical Union, 38(6), 913-920.

Suzdaleva, A., Goryunova, S., Marchuk, A., \& Borovkov, V. (2017). Mobilization strategy to overcome global crisis of water consumption. IOP Conference Series: Earth and Environmental Science, 90(1), 1-7.

U.S. Bureau of Reclamation - USBR. (2001) Water Measurement Manual. Washington, WA: U.S. Department of the Interior. 
U.S. Geological Survey - USGS. (2010) Discharge Measurements at Gaging Stations. Washington, WA: USGS.

Villela, S. M., \& Mattos, A. (1975) Hidrologia Aplicada. São Paulo, SP: McGraw-Hill. 245 p.

Walter, C., \& Tullos, D. D. (2010). Downstream channel changes after a small dam removal: using aerial photos and measurement error for context; Calapooia River, Oregon. River Research and Applications, 26(10), 12201245 .

Wei, W., Chang, Y., \& Dai, Z. (2014). Streamflow changes of the Changjiang (Yangtze) River inthe recent 60 years: impacts of the East Asian summer monsoon, ENSO, and human activities. Quaternary International, 336, 98107.

World Water Development Report - WWDR. (2019) Leaving no one behind. Paris: UNESCO. 201 p.

\section{Contribuições dos Autores}

Ana Claudia Pereira Carvalho: contribuiu com o monitoramento pluviométrico e fluviométrico em campo, na análise dos resultados e escrita do artigo.

Ana Paula Pereira Carvalho: contribuiu com o monitoramento pluviométrico e fluviométrico em campo, na análise dos resultados e escrita do artigo.

José Augusto Di Lollo: contribuiu com a análise dos resultados e escrita do artigo.

Eduardo Goulart Collares: contribuiu com a análise dos resultados e escrita do artigo.

Reinaldo Lorandi: contribuiu com a análise dos resultados e escrita do artigo.

Luiz Eduardo Moschini: contribuiu com a análise dos resultados e escrita do artigo. 